\title{
Prevalence of neural tube defects in South Australia, 1966-91: effectiveness and impact of prenatal diagnosis
}

\author{
Annabelle Chan, Evelyn F Robertson, Eric A Haan, Rosemary J Keane, Enzo Ranieri, \\ Annabel Carney
}

\begin{abstract}
Objective-To determine trends in total prevalence of neural tube defects in South Australia during 1966-91, the impact of prenatal diagnosis on birth prevalence, and the effectiveness of prenatal screening for neural tube defects in 1986-91.

Design-All births and terminations of pregnancy affected by neural tube defects and information on prenatal screening were ascertained from multiple sources including the South Australian perinatal and abortion statistics collections, birth defects register, and state maternal serum $\alpha$ fetoprotein screening programme.
\end{abstract}

Setting-Southern Australia.

Subjects-All 1058 births and terminations of pregnancy affected by neural tube defects in 1966-91.

Main outcome measures-Total prevalence and birth prevalence of individual and all neural tube defects. The proportion of screened cases detected prenatally.

Results-Total prevalence of neural tube defects

Pregnancy Outcome Unit, Epidemiology Branch, South Australian Health Commission, PO Box 6, Rundle Mall, Adelaide, South Australia 5000 Annabelle Chan, senior medical consultant Rosemary J Keane, midwife

Department of Chemical Pathology, Centre for Medical Genetics, Adelaide Children's Hospital, Adelaide Evelyn F Robertson, deputy director

Enzo Ranieri, chemist in charge, screening programmes

South Australian Birth Defects Register, Department of Medical Genetics, Centre for Medical Genetics, Adelaide Children's Hospital, Adelaide Eric A Haan, director

\section{Department of} Neurosurgery, Adelaide Children's Hospital, Adelaide

Annabel Carney, coordinator, spina bifida clinic

Correspondence to: Dr Chan.

\section{Introduction}

Neural tube defects, which include anencephaly, spina bifida, and encephalocele, are an important group of severe birth defects whose prevalence has fallen over the past six decades in many countries. The fall has been attributed to natural causes in some countries-for example, in the Republic of Ireland, where screening programmes and terminations of pregnancy are not available ${ }^{12}$ and in the United Kingdom, the Netherlands, Sweden, Hungary, and the United States before screening programmes were established in the $1980 \mathrm{~s}$. $^{13-7}$ In Australia the natural fall in prevalence initially reported in three states from 1976 to $1981^{8}$ was not sustained after $1981 . .^{9}$

The introduction of antenatal ultrasonography and population based maternal serum $\alpha$ fetoprotein screening programmes in the late 1970 s has enhanced the natural fall in prevalence. ${ }^{210-12}$ The impact of prenatal diagnosis cannot be assessed when statistics on terminations of pregnancy are lacking, ${ }^{1013}$ but where these statistics are available stable prevalence or fluctuations in prevalence with no time trends have been reported. ${ }^{2}$

We conducted this study to determine the total prevalence of neural tube defects in South Australia for the years 1966-91, the impact of prenatal diagnosis on birth prevalence (excluding terminations) during this period, and the effectiveness of prenatal screening for neural tube defects in 1986-91. South Australia has a population of 1.4 million, with one million living in the capital city, Adelaide. There are about 20000 babies born of at least $400 \mathrm{~g}$ birth weight or 20 weeks' gestation annually. Details of pregnancy and birth, including congenital abnormalities, are notified by midwives to the perinatal statistics collection. Termination of pregnancy before 28 weeks' gestation has been legal in South Australia since 1970 and about 4500 terminations are notified annually under regulations. The South Australian birth defects register obtains further notifications of congenital abnormalities from several other sources for children whose abnormalities are identified after the early neonatal period and before the age of 5 .

The chemical pathology department at Adelaide Children's Hospital established a pilot maternal serum $\alpha$ fetoprotein screening programme for neural tube defects in 1977-82, which included about a quarter of women who gave birth in South Australia in that period. A full state-wide programme has been operating since May 1982, and this has included an increasing proportion of women who have given birth, from $52 \%$ in 1983 to $81 \%$ in $1986-91$. Doctors notify to the programme fetuses or babies with neural tube defects in women screened. Antenatal ultrasonography has been used in South Australia since the 1970s, and data from the perinatal statistics collection show that the proportion of women giving birth who had had at least one antenatal ultrasound examination was $64 \%$ in 1981 and $92 \%$ in 1991. 
reports on perinatal deaths, post-neonatal deaths, and terminations of pregnancy for congenital abnormalities; reports from doctors; and hospital case records, including those of the department of neurosurgery at Adelaide Children's Hospital (the only paediatric neurosurgical unit in South Australia).

For 1966-73, data on children born with anencephaly and spina bifida were collected by the department of neurosurgery from stillbirth and death records, from the hospital's case records, and through postal inquiry to all obstetric hospitals in South Australia. ${ }^{8}$ For $1974-80$, before the establishment of the perinatal statistics collection, the reports of the Australian Bureau of Statistics on perinatal deaths due to neural tube defects were also used.

\section{STATISTICAL ANALYSIS}

Total prevalence was calculated by dividing the total number of live births, stillbirths, and terminations of pregnancy affected by a neural tube defect by the total number of live births and stillbirths for each year, and expressing this as a rate per 1000 births. Birth prevalences excluded terminations of pregnancy and were based on only live births and spontaneous stillbirths with neural tube defects.

We analysed time trends for total prevalence of all neural tube defects and individual defects for 1966-91 using Poisson regression analysis, ${ }^{15}$ where the dependent variable was the number of defects and the predictor variable was year. We repeated the analysis for birth prevalence, excluding terminations of pregnancy. In view of the aetiological heterogeneity of neural tube defects ${ }^{716}$ and the suggestion that they should be analysed separately as single and multiple defects, ${ }^{7}$ we repeated analyses for encephalocele for single defects only. Analyses for single defects only for anencephaly and spina bifida could not be done as detailed information on these defects was not available in all the earlier years.

Comparisons of birth prevalences between 1966 and 1991 were made for all neural tube defects and individually for anencephaly, spina bifida, and encephalocele by calculating relative risks (and 95\% confidence intervals) for the defects with the Epi Info program. ${ }^{17}$

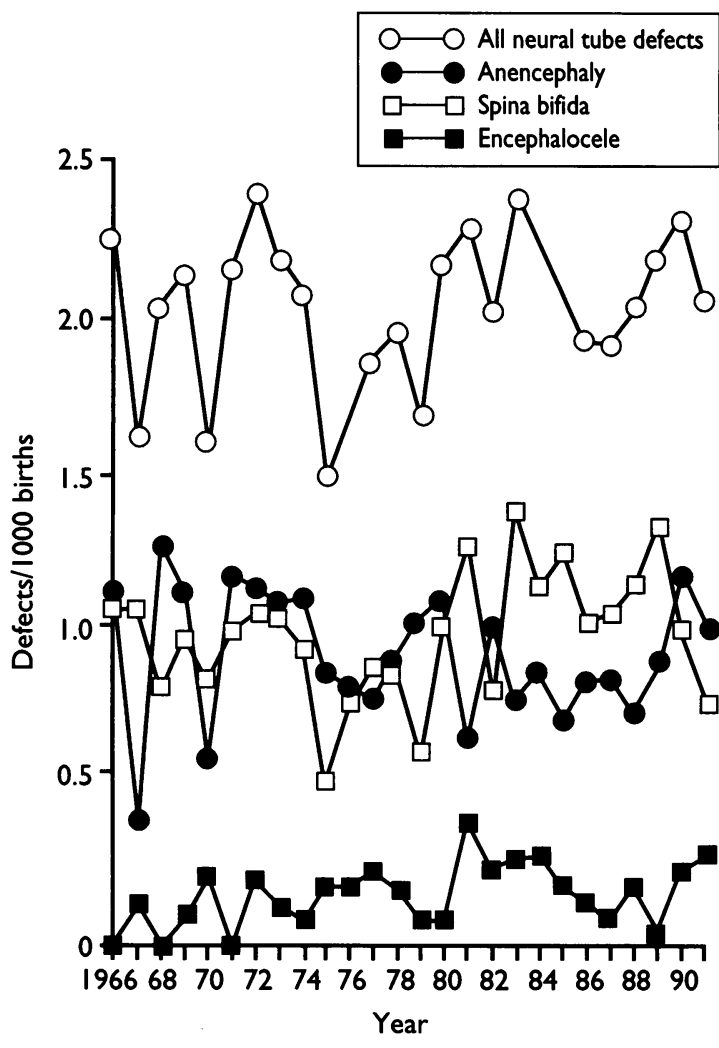

FIG 1-Total prevalence of neural tube defects, South Australia, 1966-91

\section{Results}

Table I shows the total prevalence and birth prevalence of neural tube defects in South Australia for 196691 . Figures 1 and 2 show the total prevalence and birth prevalence for all neural tube defects and for individual defects. As there were no terminations for neural tube defects until 1978, total prevalence and birth prevalence were the same for 1966-77.

The annual total prevalence of neural tube defects in South Australia in 1966-91 fluctuated between 1.49 and $2 \cdot 37 / 1000$ births with no upward or downward

TABLE I-Total prevalence and birth prevalence of neural tube defects, South Australia, 1966-1991

\begin{tabular}{|c|c|c|c|c|c|c|c|c|c|c|c|}
\hline \multirow[b]{2}{*}{$\begin{array}{l}\text { Year of } \\
\text { birth or } \\
\text { termination }\end{array}$} & \multirow[b]{2}{*}{$\begin{array}{c}\text { Total } \\
\text { births }\end{array}$} & \multicolumn{2}{|c|}{ No with anencephaly } & \multicolumn{2}{|c|}{ No with spina bifida } & \multicolumn{2}{|c|}{ No with encephalocele } & \multirow[b]{2}{*}{$\begin{array}{l}\text { Births and } \\
\text { terminations } \\
\text { of pregnancy }\end{array}$} & \multicolumn{3}{|c|}{ All neural tube defects } \\
\hline & & $\begin{array}{l}\text { Births and } \\
\text { terminations } \\
\text { of pregnancy }\end{array}$ & Births & $\begin{array}{l}\text { Births and } \\
\text { terminations } \\
\text { of pregnancy }\end{array}$ & Births & $\begin{array}{l}\text { Births and } \\
\text { terminations } \\
\text { of pregnancy }\end{array}$ & Births & & $\begin{array}{l}\text { Rate/ } \\
1000 \\
\text { births }\end{array}$ & Births & $\begin{array}{l}\text { Rate/ } \\
1000 \\
\text { births }\end{array}$ \\
\hline 1966 & 20556 & 24 & 24 & 23 & 23 & 0 & 0 & 47 & $2 \cdot 29$ & 47 & $2 \cdot 29$ \\
\hline 1967 & 20597 & 8 & 8 & 23 & 23 & 2 & 2 & 33 & 1.60 & 33 & 1.60 \\
\hline 1968 & 21424 & 27 & 27 & 17 & 17 & 0 & 0 & 44 & 2.05 & 44 & 2.05 \\
\hline 1969 & 22185 & 25 & 25 & 21 & 21 & 1 & 1 & 47 & $2 \cdot 12$ & 47 & $2 \cdot 12$ \\
\hline 1970 & 22817 & 13 & 13 & 19 & 19 & 4 & 4 & 36 & 1.58 & 36 & 1.58 \\
\hline 1971 & 23246 & 27 & 27 & 23 & 23 & 0 & 0 & 50 & $2 \cdot 15$ & 50 & $2 \cdot 15$ \\
\hline 1972 & 22073 & 25 & 25 & 23 & 23 & 4 & 4 & 52 & $2 \cdot 36$ & 52 & $2 \cdot 36$ \\
\hline 1973 & 20651 & 22 & 22 & 21 & 21 & 2 & 2 & 45 & $2 \cdot 18$ & 45 & $2 \cdot 18$ \\
\hline 1974 & 20417 & 22 & 22 & 19 & 19 & 1 & 1 & 42 & 2.06 & 42 & 2.06 \\
\hline 1975 & 20175 & 17 & 17 & 10 & 10 & 3 & 3 & 30 & 1.49 & 30 & 1.49 \\
\hline 1976 & 19157 & 15 & 15 & 14 & 14 & 3 & 3 & 32 & 1.67 & 32 & 1.67 \\
\hline 1977 & 19438 & 15 & 15 & 17 & 17 & 4 & 4 & 36 & 1.85 & 36 & 1.85 \\
\hline 1978 & 18736 & 17 & 13 & 16 & 16 & 3 & 3 & 36 & 1.92 & 32 & 1.71 \\
\hline 1979 & 18641 & 19 & 12 & 11 & 11 & 1 & 1 & 31 & 1.66 & 24 & 1.29 \\
\hline 1980 & 18638 & 20 & 11 & 19 & 19 & 1 & 1 & 40 & $2 \cdot 15$ & 31 & 1.66 \\
\hline 1981 & 19052 & 12 & 3 & 24 & 18 & 7 & 6 & 43 & $2 \cdot 26$ & 27 & 1.42 \\
\hline 1982 & 19128 & 19 & 7 & 15 & 12 & 4 & 4 & 38 & 1.99 & 23 & 1.20 \\
\hline 1983 & 19800 & 15 & 7 & 27 & 20 & 5 & 3 & 47 & 2.37 & 30 & 1.52 \\
\hline 1984 & 20281 & 17 & 4 & 23 & 11 & 5 & 3 & 45 & $2 \cdot 22$ & 18 & 0.89 \\
\hline 1985 & 19833 & 14 & 5 & 24 & 12 & 3 & 2 & 41 & 2.07 & 19 & 0.96 \\
\hline 1986 & 19800 & 16 & 3 & 20 & 8 & 2 & 2 & 38 & 1.92 & 13 & 0.66 \\
\hline 1987 & 19395 & 16 & 2 & 20 & 10 & 1 & 1 & 37 & 1.91 & 13 & 0.67 \\
\hline 1988 & 19530 & 14 & 1 & 22 & 9 & 3 & 3 & 39 & 2.00 & 13 & 0.67 \\
\hline 1989 & 19823 & 17 & 1 & 26 & 12 & 0 & 0 & 43 & $2 \cdot 17$ & 13 & 0.66 \\
\hline 1990 & 19988 & 23 & 0 & 19 & 6 & 4 & 0 & 46 & $2 \cdot 30$ & 6 & 0.30 \\
\hline 1991 & 19749 & 20 & 1 & 15 & 4 & 5 & 2 & 40 & 2.03 & 7 & 0.35 \\
\hline Total & 525130 & 479 & 310 & 511 & 398 & 68 & 55 & 1058 & $2 \cdot 01$ & 763 & 1.45 \\
\hline
\end{tabular}

$\star$ Births=livebirths plus spontaneous stillbirths.

There were no terminations for neural tube defects before 1978 


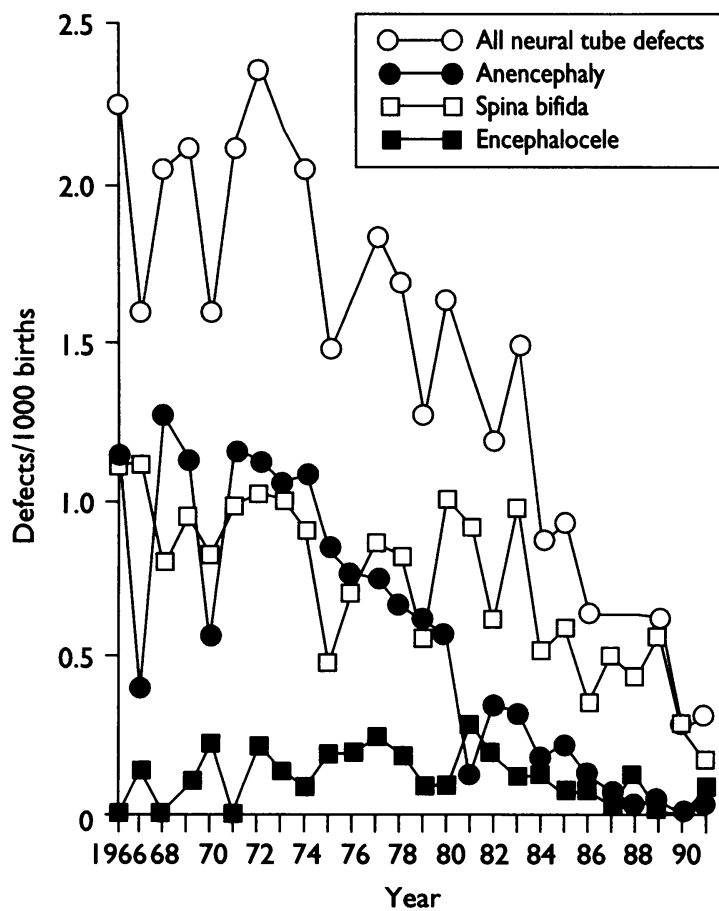

FIG 2-Birth prevalence of neural tube defects, South Australia, 1966-91

trend (Poisson regression, $\mathrm{p}=0.46$ ). Total prevalence for the study period was $2 \cdot 01 / 1000$ births for all neural tube defects, $0.91 / 1000$ for anencephaly, $0.97 / 1000$ births for spina bifida. No time trends were seen for anencephaly $(p=0.4)$ or spina bifida $(p=0.31)$. The prevalence of encephalocele increased significantly $(p=0.02)$, but the effect was lost when only single defects were analysed $(p=0 \cdot 19)$.

Termination of pregnancy for neural tube defects rose from 1978-91 as detection rates increased (fig 3). Birth prevalence fell by $5 \cdot 1 \%$ a year, for all neural tube defects during 1966 to $1991 \quad(\mathrm{p}<0.0001)$; the fall was significant for anencephaly $(8.6 \%$ a year, $\mathrm{p}<0.0001)$ and spina bifida (3.5\% a year, $\mathrm{p}<0.0001)$ but not for encephalocele ( $p=0.57$ for all encephaloceles and $p=0.97$ for single defects only).

Birth prevalence for all neural tube defects fell by $84 \%$, from $2 \cdot 29 / 1000$ births in 1966 to $0 \cdot 35 / 1000$ in 1991 (relative risk $=0 \cdot 16,95 \%$ confidence interval 0.07 to $0 \cdot 34$ ). The fall was $96 \%$ for anencephaly, from $1 \cdot 17$ to $0.05 / 1000$ births $(0.04,0.01$ to 0.32$)$, and $82 \%$ for spina bifida, from $1 \cdot 12$ to $0 \cdot 20 / 1000$ births $(0 \cdot 18,0.06$ to 0.52 ). No significant change in birth prevalence was seen for encephalocele.

Table II shows the cases of neural tube defects detected before 28 weeks' gestation in 1986-91. In all $80 \%$ ( $95 \%$ confidence interval $75 \%$ to $85 \%$ ) of cases were detected in the period. The percentage was higher for anencephaly $(95 \%)$ than for spina bifida $(69 \%)$ or for encephalocele $(60 \%)$

If only the women screened by maternal serum $\alpha$ fetoprotein at $16-20$ weeks' gestation or mid-trimester

TABLE II-Cases of neural tube defects detected before 28 weeks' gestation, 1986-91

\begin{tabular}{|c|c|c|c|c|c|c|c|c|}
\hline \multirow[b]{2}{*}{$\begin{array}{l}\text { Year of birth } \\
\text { or termination }\end{array}$} & \multicolumn{2}{|c|}{ Anencephaly } & \multicolumn{2}{|c|}{ Spina bifida } & \multicolumn{2}{|c|}{ Encephalocele } & \multicolumn{2}{|c|}{$\begin{array}{l}\text { All neural tube } \\
\text { defects }\end{array}$} \\
\hline & $\begin{array}{l}\text { Total No } \\
\text { of defects }\end{array}$ & $\begin{array}{l}\text { No }(\%) \\
\text { detected }\end{array}$ & $\begin{array}{l}\text { Total No } \\
\text { of defects }\end{array}$ & $\begin{array}{c}\text { No }(\%) \\
\text { detected }\end{array}$ & $\begin{array}{l}\text { Total No } \\
\text { of defects }\end{array}$ & $\begin{array}{l}\text { No (\%) } \\
\text { detected }\end{array}$ & $\begin{array}{l}\text { Total No } \\
\text { of defects }\end{array}$ & $\begin{array}{l}\text { No (\%) } \\
\text { detected }\end{array}$ \\
\hline 1986 & 16 & $15(94)$ & 20 & $14(70)$ & 2 & 0 & 38 & $29(76)$ \\
\hline 1987 & 16 & $14(88)$ & 20 & $11(55)$ & 1 & 0 & 37 & $25(68)$ \\
\hline 1988 & 14 & $14(100)$ & 22 & $13(59)$ & 3 & 0 & 39 & 27 (69) \\
\hline 1989 & 17 & $16(94)$ & 26 & $19(73)$ & 0 & 0 & 43 & $35(81)$ \\
\hline 1990 & 23 & $23(100)$ & 19 & $15(79)$ & 4 & $4(100)$ & 46 & $42(91)$ \\
\hline 1991 & 20 & $19(95)$ & 15 & $12(80)$ & 5 & $5(100)$ & 40 & $36(90)$ \\
\hline Total & 106 & $101(95)$ & 122 & $84(69)$ & 15 & $9(60)$ & 243 & $194(80)$ \\
\hline
\end{tabular}

ultrasonography, or both, were included-that is, 227 women with affected babies in 1986-91-the percentage of cases detected prenatally before 28 weeks' gestation was $85 \%$ ( $81 \%$ to $90 \%)$. The corresponding percentages for individual defects were $99 \%$ for anencephaly, $76 \%$ for spina bifida, and $64 \%$ for encephalocele. Only five of the 194 cases detected before 28 weeks' gestation were detected after 20 weeks' gestation by ultrasound examination.

\section{Discussion}

The study has shown that the total prevalence of neural tube defects in South Australia was stable during 1966-91 but that the birth prevalence fel greatly because of effective prenatal diagnosis and termination of pregnancy.

As spontaneous loss of fetuses with neural tube defects occurs, prenatal detection and termination of affected fetuses before 20 weeks' gestation may have resulted in some cases being included in the total prevalence for 1978-91 that would have been excluded from the data collected before 1978 because they had aborted spontaneously. Creasy and Alberman have estimated that $17 \cdot 4 \%$ of fetuses with neural tube defects are lost spontaneously at 12-15 weeks' gestation and $4.5 \%$ at $16-19$ weeks. ${ }^{18}$ We applied the estimates to the number of terminations at those gestations in 1978
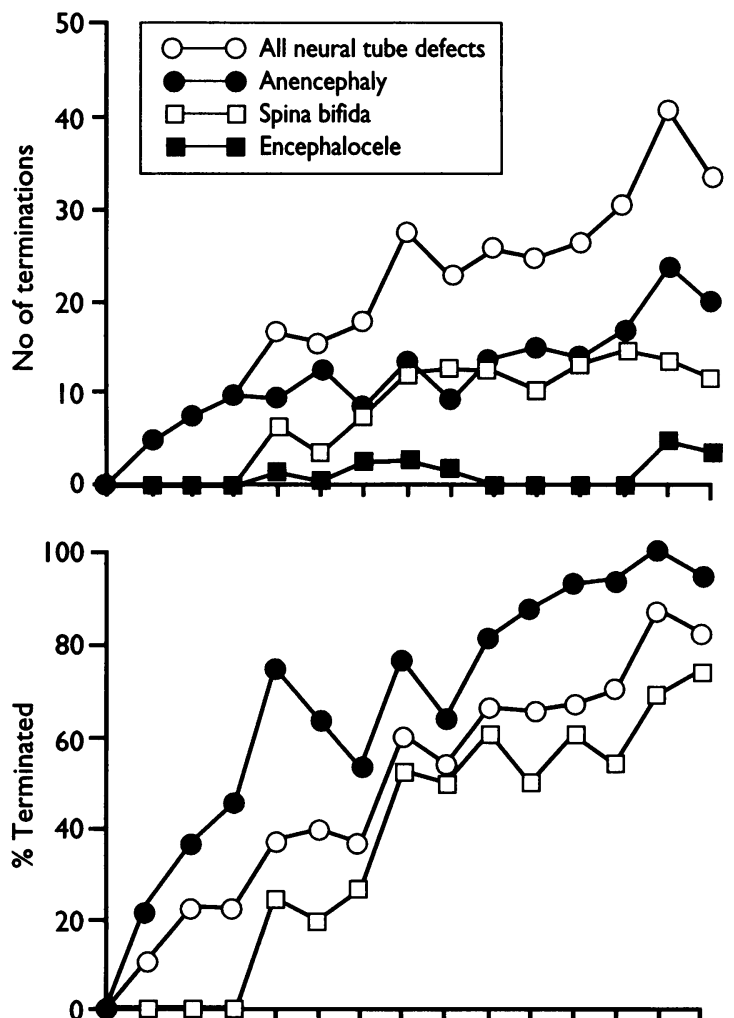

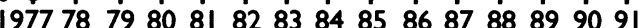

Year

FIG 3-Terminations of pregnancy for neural tube defects (top) and proportion of pregnancies affected by neural tube defects that were terminated (bottom), South Australia, 1977-91

91 to determine spontaneous losses for each year. This would have resulted in the exclusion of one fetus with a neural tube defect in each of the years 1983-7 and 1989 and of two fetuses in 1988, 1990, and 1991. Excluding these fetuses did not affect the conclusion of an absence of trend in the total prevalence of all neural tube defects for 1966-91 (Poisson regression analysis, $p=0.77$ ) or of anencephaly, the defect contributing the largest proportion of terminations $(p=0 \cdot 21)$.

The greater fall in birth prevalence for anencephaly 


\section{Public health implications}

- Most women in developed countries are now offered screening for neural tube defects and affected babies are less common

- Ascertainment of all births and terminations of pregnancy affected by neural tube defects in South Australia shows that the total prevalence remained stable during 1966-91

- Birth prevalence, however, fell by $84 \%$ as a result of screening

- Serum $\alpha$ fetoprotein concentration and ultrasonography detected $85 \%$ of affected pregnancies before 28 weeks' gestation

- Coordinated population based screening programmes and registers of birth defects allow accurate assessment of effectiveness of prenatal diagnosis and preventive measures

than for spina bifida is to be expected as anencephaly is easier to diagnose by ultrasonography and it is usually associated with a high maternal serum $\alpha$ fetoprotein concentration. Serum $\alpha$ fetoprotein concentration is not often raised in closed spina bifida (which comprised $24.6 \%$ of the spina bifida cases in 1986-91). The fall in birth prevalence and the proportion of defects detected prenatally are consistent with the findings of other centres with a population based maternal serum $\alpha$ fetoprotein screening programme and wide access to ultrasound screening in pregnancy. ${ }^{210}$ Centres without a population based serum $\alpha$ fetoprotein screening programme have generally achieved a lower proportion of prenatal diagnoses. ${ }^{29}$

The impact of prenatal diagnosis on birth prevalence is dependent not only on the sensitivity of the screening programme but also on the uptake of testing by doctors and pregnant women, presentation for antenatal care in time for screening and legal termination of pregnancy, and the attitude to termination of pregnancy of couples with affected fetuses.

Our results show the value of population based registers in accurate ascertainment of birth defects, which enables assessment of the effect of preventive strategies. The centralised maternal serum $\alpha$ fetoprotein screening programme facilitated ascertainment. Folate has been shown to reduce the rate of neural tube defects when taken before conception and in the early months of pregnancy. ${ }^{120}$ There is no formal policy on the use of folate before conception in South Australia, but the Australian National Health and Medical Research Council has recommended that women who have had an affected pregnancy or have a family history of neural tube defect should be offered genetic counselling and folic acid supplements around the time of conception ( $5 \mathrm{mg}$ daily). The council has also recently recommended (115th session, Adelaide, June 1993) that women in low risk groups should take $0.5 \mathrm{mg}$ of folic acid daily around the time of conception, that all women of childbearing age should be encouraged to increase their intake of folate rich foods, and that staple foods should be fortified with folic acid.

We thank all the midwives and doctors who notified to the collections used in this study and who responded to further requests for information; the histopathologists who provided final diagnoses for the defects; the Australian Bureau of Statistics, South Australian Branch; the staff of all the departments in this study for their support and help, especially Mr Ahmad Hanieh, director of the department of neurosurgery, Professor Donald Simpson, formerly director of the department, and Professor Anthony Pollard, formerly director of the department of chemical pathology, Adelaide Children's Hospital; and Mr Adrian Esterman, principal health statistician, South Australian Health Commission for doing the Poisson regression analyses. We also thank the committee appointed to examine and report on abortions notified in South Australia for allowing us to use the abortion statistics.

1 Kirke PN, Elwood JH. Anencephaly in the United Kingdom and Republic of Ireland. $B M F$ 1984;289:1621.

2 EUROCAT Working Group. Prevalence of neural tube defects in 20 regions of Europe and the impact of prenatal diagnosis, 1980-1986. I Epidemio Community Health 1991;45:52-8.

3 Romijn JA, Treffers PE. Anencephaly in the Netherlands: a remarkable decline. Lancet 1983;i:64-5.

4 Kallen B, Lofkvist E. Time trends of spina bifida in Sweden 1947-81. $f$ Epidemiol Community Health 1984;38:103-7.

Czeizel A. Spina bifida and anencephaly. BMf 1983;287:429.

6 Stein SC, Feldman JG, Friedlander M, Klein RJ. Is myelomeningocoele a disappearing disease? Paediatrics 1982;69:511-4.

7 Khoury MJ, Erickson JD, James LM. Etiologic heterogeneity of neural tube defects: clues from epidemiology. $A m \mathcal{F}$ Epidemiol 1982;115:538-48.

8 Bower C, Hobbs M, Carney A, Simpson D. Neural tube defects in Western Australia 1966-81 and a review of Australian data 1942-81. I Epidemiol Community Health 1984;38:208-13.

9 Bower C, Raymond M, Lumley J, Bury G. Trends in neural tube defects 1980 1989. Med F Aust 1993;158:152-4.

10 Ferguson-Smith MA. The reduction of anencephalic and spina bifida births by maternal serum alpha-fetoprotein screening. Br Med Bull 1983;39:365-72.

11 Cuckle $\mathrm{H}$, Wald $\mathrm{N}$. The impact of screening for open neural tube defects in England and Wales. Prenatal Diagnosis 1987;7:91-9.

12 Owens JR, McAllister E, Harris F, West L. 19-year incidence of neural tube defects in area under constant surveillance. Lancet 1981;ii:1032-5.

13 Centers for Disease Control. Spina bifida incidence at birth-United States, 1983-1990. MMWR 1992;41:497-500.

14 International Clearinghouse for Birth Defects Monitoring Systems. Annual report. CBDMS, 1988.

15 Gebski V, Leung O, McNeil D, Lunn D. Statistical package for interactive data analysis (SPIDA). User's Manual, Version 6. Sydney: Statistical Computing Laboratory, 1992

16 Holmes LB, Driscoll SG, Atkins LA. Etiologic heterogeneity of neural tube defects. N Engl f Med 1976;294:365-9.

17 Dean AG, Dean JA, Burton AH, Dicker RC. Epi Info version 5: a word processing, database and statistics programme for epidemiology on microcomputers. Stone Mountain, Georgia: USD, 1990.

18 Creasy MR, Alberman ED. Congenital malformations of the central nervous system in spontaneous abortions. 7 Med Genet 1976;13:9-16.

19 MRC Vitamin Study Research Group. Prevention of neural tube defects: results of the Mecical Research Council vitamin study. Lancet 1991;338: 131-7.

20 Czeizel AE, Dudas I. Prevention of the first occurrence of neural-tube defects by periconceptional vitamin supplementation. $N$ Engl F Med 1992;327: 1832-5.

(Accepted 2 fuly 1993)

\section{Corrections}

How frequently should basic cardiopulmonary

resuscitation training be repeated to maintain adequate skill?

An editorial error occurred in this paper by Hubert J J M Berden and others (12 June, $\mathrm{pp}$ 1576-7). The figure suggests that resuscitation skills were measured only once in each group at time 0 whereas two measurements were made, immediately before and after training in resuscitation was given. Before training all three groups accrued about 38 penalty points, while after training they all accrued about 15 points.

\section{Lifelong exercise and stroke}

An editorial error occurred in this paper by Roger Shinton and Gian Sagar (24 July, pp 231-4). The first sentence in the second paragraph of the methods section should have read: "Between 1 October 1988 [not 1989] and 30 September 1990 we recruited men and women who had just had their first stroke and were aged 35-74"

\section{Urinary microalbumin excretion in early pregnancy and} gestational age at delivery

An editorial and an authors' error occurred in this paper by Ivan Perry and others (14 August, pp 420-1). In the table the second quartile of distribution of albumin $c$ reatinine ratio should be 0.35 to 0.62 . In the first sentence of the second paragraph the study group was defined incorrectly; the group comprised 692 healthy nulliparous pregnant women and 11 women with chronic hypertension referred for antenatal care before 31 weeks' gestation. 